\title{
PARA O LAR: AS MULHERES QUE DEIXARAM O MER- CADO DE TRABALHO PARA SE DEDICAREM À CASA E À FAMÍLIA
}

\section{Carolina Freddo Fleck' \\ Marcos Vinicius Dalagostini Bidarte ${ }^{2}$ \\ Elena Maria Billig Mello ${ }^{3}$}

Resumo: $\bigcirc$ objetivo desta pesquisa foi identificar as mulheres que migraram do mercado de trabalho para o exercício da profissão do lar em Santana do Livramento, RS, Brasil, bem como os principais fatores para tal atitude. As entrevistas foram realizadas por meio da técnica bola de neve e utilizou-se análise de conteúdo para tratar os dados. Os resultados demonstram que os fatores familiares foram os principais responsáveis pela transição do mercado de trabalho para a profissão do lar pelas mulheres, o que é explicado historicamente por ser o espaço privado destinado a elas, enquanto aos homens destina-se o espaço público.

Palavras-Chave: Gênero; profissão do lar; afazeres domésticos.

Abstract: The aim of this paper was to identify the woman who migrated from the labor market to the home profession in Santana do Livramento, Rio Grande do Sul, Brazil, as well as the main factors for such an attitude. The interviews were realized using the snowball technique and was used content analysis to treat the data. The results show that family factors were responsible for the transition from the labor market to the home profession by women, which is explained historically as the private space destined for them, while men are destined for the public space.

Keywords: Gender; home profession; household chores.

\section{Introdução}

Historicamente a mulher tem exercido a responsabilidade, muitas vezes sozinha, de dedicar-se aos cuidados do lar, dos filhos, do marido e demais familiares, enquanto o homem é incumbido do sustento econômico do lar e da ordem familiar. Dessa forma, à mulher era reservada à esfera privada, sendo afastada da sociedade,

\footnotetext{
1 Doutora em Administração pela Universidade Federal do Rio Grande do Sul. Professora Adjunta da Universidade Federal do Pampa. E-mail: carolinafleck@unipampa.edu.br

2 Mestrando do Curso de Pós-Graduação em Administração pela Universidade Federal do Pampa. E-mail: viniciusbidarte@hotmail.com

3 Doutora em Educação pela Universidade Federal do Rio Grande do Sul. Professora Adjunta da Universidade Federal do Pampa. E-mail: elenamello@unipam.edu.br
} 
e ao homem a esfera pública. Esse tipo de cultura social persiste há séculos em nível mundial, pois tanto as mulheres quanto os homens são educados de formas distintas e assumem, ao longo de suas vidas, diferentes papéis sociais. Por essa razão, o trabalho doméstico sempre foi e ainda é praticado, via de regra, por mulheres.

A partir da década de 1970, as manifestações sociais, a evolução sociocultural e a busca por direitos das mulheres fizeram com que elas entrassem mais intensamente no mercado de trabalho e iniciassem a ocupação de cargos de chefia antes somente ocupados por homens (BRUSCHINI et al., 2011; SCHLICKMANN e PIZARRO, 2013). As manifestações sociais transformaram o papel da mulher no trabalho, na familia, na política, na religião, na economia, entre outras esferas (BRUSCHINI, 2007; DINIZ, 2004; SANTOS, 2008) e desencadearam uma releitura na divisão dos papéis desempenhados pelo homem e pela mulher (BRUSCHINI, 1985; SANTOS e DINIZ, 2011).

O Informe intitulado "Trabajo al servicio del desarrollo humano", discorre sobre o trabalho das mulheres em relação ao dos homens, o que possibilita reflexões sobre questões de gênero e a situação das mulheres, a seguir um trecho:

\begin{abstract}
Mientras que las mujeres llevan a cabo el 52 por ciento de todo el trabajo mundial, se siguen constatando desigualdades patentes en su distribución. Las mujeres tienen menos probabilidades de tener un trabajo remunerado que los hombres, y realizan 3 de cada 4 horas de trabajo no pagado. En cambio, a los hombres les corresponden 2 de cada 3 horas de trabajo remunerado. Dado que las mujeres suelen asumir el cuidado de los miembros de la familia, el Informe advierte que es probable que estas desigualdades se intensifiquen a medida que la población envejece (PNUD, 2015, p. 01).
\end{abstract}

As mulheres, ao ausentarem-se ou afastarem-se do mercado de trabatho e retornarem, de forma exclusiva, ao trabalho no âmbito doméstico, fazem por motivos impostos ou escolhidos. Em um estudo pontual, Bruschini (1985) apontou que fatores individuais (como idade, estado civil e escolaridade), familiares (como posição na família e presença, número e idade dos filhos), estruturais (como setores de atividade da economia), desigualdades salariais e condições de trabalho (como posição na ocupação, carteira de trabalho e contribuição à Previdência Social) atuam no processo decisório das mulheres de ingressar, permanecer ou abandonar o mercado de trabalho.

Há mulheres, por exemplo, que optam por realizar as atividades domésticas e os cuidados com a família em detrimento da sua vida profissional, o que acaba ainda sendo visto como seu dever e direito. A literatura acadêmica brasileira tem sinalizado que as mulheres são os indivíduos que abandonam o mercado de trabalho em razão do casamento, dos filhos e das atividades domésti- 
cas (BRUSCHINI et al., 2011; MADALOZZO; MARTINS e SHIRATORI, 2010; MELO e SABBATO, 2011; SANTOS e DINIZ, 2011). Estas mesmas razões são apontadas pela literatura acadêmica internacional, como no caso da mexicana (CALDERÓN e CAMPOS RÍOS, 2013) e norte americana (HEWLETT e LUCE, 2005). Além dessas razões, as mulheres também abandonam o mercado de trabalho por ameaças e censuras dos maridos, no México (FUNK; LANG e OSTERHAUS, 2005) e por ameaças de violência ou violência real por parte dos maridos, na Índia (KABEER et al., 2012; SEN, 1998).

$\mathrm{Na}$ presente pesquisa, assume-se que o fenômeno da migração de sujeitos, em especial do gênero feminino, de funções remuneradas no mercado de trabalho para a dedicação a atividades domésticas e cuidados com a família ocorre da mesma forma no município gaúcho de Santana do Livramento, Brasil. Para tanto, pretende-se identificar as mulheres que migraram do mercado de trabalho para o exercício da profissão do lar, bem como os principais fatores para tal atitude, e analisar o (auto)reconhecimento do trabalho no âmbito doméstico pelos indivíduos profissionais do lar. Assim sendo, apresenta-se, a seguir, uma breve história da mulher no mercado de trabalho e a profissão do lar. Após, são apresentados os procedimentos metodológicos. A apresentação e análise dos resultados e as considerações finais compõem a penúltima e a última seção, respectivamente.

\section{A Mulher e o Mercado de Trabalho: breve história}

Com o progresso tecnológico ocasionado pela Revolução Industrial durante o século XIX, as mulheres passaram a trabalhar operando máquinas em fábricas e a serem exploradas sob diversas formas, dentre elas econômica e trabalhista. O trabalho remunerado exercido pelas mulheres nas fábricas era considerado apenas um complemento da renda familiar, uma vez que o responsável pelo sustendo econômico do lar era o homem (SANTOS, 2008).

No século XX, o ingresso das mulheres no mercado de trabalho aumentou durante a I Guerra Mundial (1914-1918) e se intensificou com a II Guerra Mundial (1939-1945), quando os homens eram escalados para as frentes de bataIhas. As mulheres começaram a assumir a posição desses homens no mercado de trabalho e os negócios familiares (SCHLICKMANN e PIZARRO, 2013). Ademais, intensos movimentos sociais surgiram e colocaram em debate a divisão do trabalho entre os homens e as mulheres, permitindo que estas, principalmente das classes média e alta, saíssem do âmbito doméstico para o exercício do trabalho remunerado no mercado de trabalho (SANTOS; DINIZ, 2011).

No Brasil, durante a década de 1950, a intensificação do processo de urbanização e industrialização foi responsável pela inserção de um grande número de muIheres no mercado de trabal ho exercendo atividades remuneradas. A partir da dé- 
cada de 1970, o trabalho feminino remunerado ganhou força através do aumento da escolaridade e do acesso à informação e às universidades, e na década seguinte, a inclusão das mulheres no mercado de trabalho foi impulsionada através de empregos que demandavam habilidades sociais e intelectuais, não mais físicas (BRUSCHINI, 1996; BRUSCHINI et al., 2011; SOARES, 2008; SANTOS, 2008).

Simultaneamente com as transformações educacionais e culturais, novos métodos contraceptivos favoreceram mudanças demográficas e, consequentemente, reduziram $\circ$ tamanho das famílias. Com base em dados do IBGE (2010a), o número de filhos por mulher é de 1,94, e o tamanho das famílias diminui de 3,3 pessoas em 2002 para 3,1 pessoas em 2009. Com isso, pode-se dizer que a queda da taxa de fecundidade possibilitou a "libertação" da mulher para o mercado de trabalho (SANTOS, 2008).

As transformações econômicas deram-se, sobretudo, na necessidade da mulher em contribuir para a renda familiar devido ao aumento no nível de consumo. Em 2009, o percentual chegou a quase $66 \%$, contra $39 \%$ em 1992 (CAMARANO, 2010). Os indicadores de participação econômica no Brasil, entre os anos de 2002 e 2009, mostram que a População Economicamente Ativa (PEA) aumentou de 36,5 milhões para 44,4 miIhões, a taxa de atividade passou de $50,3 \%$ para $52,7 \%$ e a porcentagem de mulheres cresceu de 42,5\% para 43,9\% (BRUSCHINI et al., 2011).

Apesar do progresso, há um caminho a ser trilhado pelas mulheres no sentido de atingir melhores números entre indivíduos empregados e taxas de atividades. Os baixos indicadores mostram, de certa forma, que as mulheres ainda são as responsáveis pelo exercício de atividades domésticas e cuidados com os filhos e outros familiares e enfermos. Estes fatores fazem com que a mulher deixe de realizar atividades econômicas para desempenhar cuidados com a casa e familia (BRUSCHINI et al., 2011).

\section{Profissão do Lar}

Vivemos em uma sociedade caracterizada pelas relações de poder e dominação, em que os comportamentos dos sujeitos são designados a partir do sexo primordial, o do homem. $\bigcirc$ masculino dita posições e percepções. Por isso, reflexões sobre questões relacionadas a gênero perpassam distinções biológicas e necessitam ser entendidas também a partir de diferenças advindas do contexto histórico-cultural, como, por exemplo, a muIher ocupando o espaço privado, sendo responsável pela criação dos filhos e pelo cuidado com a casa, e o homem tendo como seu o espaço público.

Carvalho (2011, p. 106) apresenta uma discussão interessante no que se refere 
à questão da dualidade gênero masculino e feminino, ancorada em Scott (1995):

[...] na abordagem de Scott, a percepção do gênero como parte de um sistema simbólico que permite a diferentes sociedades classificar, diferenciar e hierarquizar não apenas homens e mulheres, mas instituições, ações sociais, elementos da natureza, ocupações, tudo, enfim, leva o/a pesquisador/a a observar as referências e o poder explicativo do gênero em contextos em que as questões da sexualidade, reprodução, crianças e família não são aparentemente centrais (Scott, 1995) - como a arte, a política, a economia, o trabalho ou a escola, por exemplo.

Exercer a profissão do lar é realizar afazeres domésticos, que demandam por conhecimentos e habilidades, muita dedicação e tempo (SANTOS, 2008), e não necessariamente possui remuneração (MELO; CONSIDERA e SABBATO, 2007; MELO e CASTILHO, 2009; SANTOS, 2008; SANTOS e DINIZ, 2011). Profissão essa que, muitas vezes, nem é considerada como profissão (BRASIL/MTE, 2014) e, na maioria das vezes, somente é exercida por mulheres. Sendo assim aceito como natural pela sociedade.

Os afazeres domésticos incluem tarefas manuais, como: cozinhar, lavar louça, lavar e passar roupa, limpar e organizar a casa, limpar o terreno ou quintal que circunda o domicilio, etc., e tarefas não manuais, como: cuidar dos filhos, dos doentes, dos idosos e dos animais domésticos, fazer as compras no supermercado e feira, administrar a casa e o cotidiano doméstico e familiar, entre outras (BRUSCHINI, 1985; 2006; DURAN, 1983; SANTOS, 2008).

A vida e os afazeres domésticos são consequências de uma posição imposta à mulher hierarquicamente, que a mantém aprisionada na esfera privada e afastada da sociedade (DURAN, 1983; SANTOS, 2008), e socialmente, tentando fazer acreditar que o espaço doméstico atribuído às mulheres deriva de suas aptidões para serem mães (SAFFIOTI, 1987). Como resultado, há a invisibilidade do trabalho doméstico e a desvalorização do indivíduo que o exerce.

O sistema capitalista possui uma concepção de trabalho que descarta o trabaIho que não produza lucro. Para Marx (1988), somente é considerado trabalhador o individuo que emprega a sua força de trabalho no processo de produção de mais-valia. É justamente nesse ponto que a profissão do lar "não é reconhecida por não ser qualificada como produtora de benefícios econômicos" (SANTOS, 2008, p. 64).

As mulheres, geralmente, exercem a profissão do lar em período integral devido aos afazeres domésticos demandarem muito tempo para sua realização, e neste caso, a renda familiar poderá provir da realização do trabalho remunerado por outro membro da família, como marido ou filhos (SANTOS, 2008). Segundo os dados do IBGE (2014), a média de horas semanais gastas em afazeres domésticos, por 
pessoas de 10 anos ou mais, revela que as mulheres dedicam 25,3 horas semanais, enquanto os homens apenas 10,9 horas. A média de horas semanais gastas em afazeres domésticos, para as mulheres, aumenta conforme a idade e quantidade de filhos e a posição na família (cônjuge ou chefe de família) e diminui à medida que aumenta o nivel de escolaridade e o de rendimento (BRUSCHINI, 2006, 2007).

Considerando a média de horas semanais gastas em afazeres domésticos pelos indivíduos, especialmente mulheres, "seria legítimo considerar esta categoria um trabalho não-remunerado e não mais inatividade econômica" (BRUSCHINI, 2006, p. 331). O trabalho doméstico sempre foi considerado inatividade econômica, permanecendo ainda na invisibilidade das estatísticas oficiais, apesar da inserção de duas perguntas nos questionários da Pesquisa Nacional por Amostra de Domicilios sobre afazeres domésticos, a primeira em 1992 e a segunda em 2001 (BRUSCHINI, 2006).

No Brasil, a profissão do lar foi regulamentada através da Lei n. 8.213, de 24 de julho de 1991, somente para fins previdenciários e assegura poucos benefícios, os mesmos já garantidos aos demais trabalhadores, como aposentadoria por idade, invalidez e por tempo de serviço (BRASIL, 1991). De acordo com o Ministério da Previdência e Assistência Social (2015b), o profissional do lar poderá gozar dos benefícios previdenciários devido a sua idade, sendo 65 anos para os homens e 60 anos para as mulheres (trabalhadores urbanos) e de 60 anos para homens e 55 anos para as mulheres (trabalhadores rurais, indígenas, entre outros). A aposentadoria por idade somente poderá ser requerida após 180 meses de contribuição à Previdência Social e o cumprimento da idade (BRASIL, 2015b).

Quanto às contribuições para a Previdência Social, o indivíduo profissional do lar que possuir renda ou não, poderá se inscrever e deverá realizar contribuições mensais para obter acesso aos benefícios previdenciários. $\bigcirc$ indivíduo optará por enquadrar-se no segurado facultativo (desde que não disponha de uma renda própria, mas que por opção decida realizar as contribuições) ou no facultativo de baixa renda (desde que não possua renda própria, que seu trabalho seja dedicado exclusivamente para a residência, e que seja pertencente à familia de baixa renda, para que as suas contribuições sejam de $5 \%$ sobre o salário mínimo vigente) (BRASIL, 2015a). Na seção subsequente são apresentados os procedimentos metodológicos adotados na presente pesquisa.

\section{Procedimentos Metodológicos}

A presente pesquisa caracteriza-se como exploratório-descritiva, com abordagem qualitativa (COLLIS e HUSSEY, 2005). O método de pesquisa utilizado foi o estudo de caso, no sentido de compreender e descrever acontecimentos e contextos complexos (ARAÚJO et al., 2008; YIN, 2010). Destaca-se que não se buscou o aprofundamento indicado por Yin (2010), mas sim uma 
análise inicial do contexto do município de Santana do Livramento, Rio Grande do Sul, Brasil, de modo que deve ser profundamente explorado no futuro.

A técnica de coleta de dados se deu por entrevistas com seleção de sujeitos por meio da "bola de neve", apropriando-se de uma abordagem em cadeia (HAIR et al., 2005). Os sujeitos de pesquisa foram 9 mulheres moradoras do município gaúcho de Santana do Livramento, sendo que a primeira entrevistada foi escolhida pelo pesquisador por conveniência. A bola de neve foi encerrada por saturação quando não foi mais possivel a identificação de novos sujeitos por meio de indicações pela entrevistada de número 9.

Cabe a ressalva de que a pesquisa com abordagem qualitativa não sugere amostragem de um grande número de participantes (CRESWELL, 2007) e de que a presente pesquisa não representa o total de mulheres que migraram do mercado de trabalho para o exercício da profissão do lar no município gaúcho estudado. A Figura 1 ilustra o desenvolvimento da técnica bola de neve entre as entrevistadas.

Figura 1 - Desenvolvimento da técnica bola de neve entre as entrevistadas

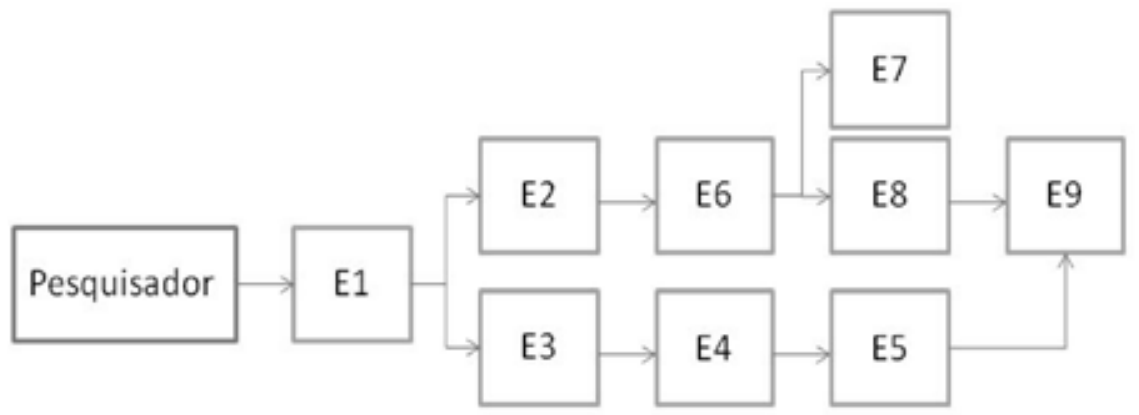

Fonte: Elaboração Própria.

Algumas informações sobre os indivíduos profissionais do lar somente são conhecidas através de técnicas específicas, como entrevistas (BRUSCHINI, 2006). Para tanto, optou-se pela entrevista semiestruturada como técnica de coleta de dados (GIL, 2012). O roteiro de entrevista contemplou questões demográficas e questões-chaves sobre a transição do mercado de trabalho para o exercício da profissão do lar e o (auto)reconhecimento do trabalho no âmbito doméstico pelas profissionais do lar, formuladas pelos autores com base, principalmente, nos estudos de Bruschini (1985, 2006, 2007), Bruschini et al. (2011), Melo, Considera e Sabbato (2007), Melo e Sabbato (2011), Saffioti (1987), Santos (2008) e pesquisas do IBGE (2010a; 2010b). As entrevistas foram realizadas entre os meses de maio de 2014 e janeiro de 2015 e tiveram a duração média de 1 h. 
Os dados foram analisados por meio da análise de conteúdo, permitindo a construção de categorias a critério dos autores (BARDIN, 2011), conforme apresentadas e analisadas na próxima seção. Destaca-se que se respeitaram os critérios de validade dos dados coletados na pesquisa qualitativa, como a exaustividade, a homogeneidade, a exclusividade, a objetividade e a adequação (MORAES, 1999).

\section{Apresentação e Análise dos Resultados}

A seção de apresentação e análise dos resultados está estruturada em três subseções, a saber: perfil demográfico das entrevistadas; a transição do mercado de trabalho para o exercício da profissão do lar; e o (auto)reconhecimento do trabalho no âmbito doméstico pelas profissionais do lar.

\section{Perfil demográfico das entrevistadas}

O perfil demográfico das entrevistadas é apresentado na Tabela 1. Observa-se a predominância da cor branca, estado civil casadas, com composição familiar média de 3 integrantes e com número de filhos médio de 1. Considerando a média do número de filhos e a do número de tamanho das famílias das entrevistadas, nota-se que são números abaixo dos dados brasileiros apresentados pela pesquisa do IBGE (2010a). De acordo com o IBGE (2014), o indicador de fecundidade no Brasil entre o período de 2000 a 2013 apresentou queda de $26 \%$ (de 2,39 filhos por mulheres para 1,77); por outro lado, o percentual de arranjos familiares compostos por casais sem filhos no país passou de $14,6 \%$ para $19,4 \%$ no período de 2004 a 2013 - aumento de 33\%. Uma das explicações para o crescimento da proporção de casais sem filhos é em virtude da redução das taxas de fecundidade.

Tabela 1 - Perfil demográfico das entrevistadas

\begin{tabular}{|c|c|c|c|c|c|c|}
\hline Entrevistada & Cor & Escolaridade & $\begin{array}{c}\text { Estado } \\
\text { Civil } \\
\end{array}$ & Idade & $\begin{array}{c}\text { Composição } \\
\text { Familiar }\end{array}$ & Filhos \\
\hline 1 & Branco & E.S.I. & $\mathrm{C}$ & 55 & 3 & 1 \\
\hline 2 & Branco & E.M.I. & $\mathrm{C}$ & 55 & 4 & 2 \\
\hline 3 & Branco & E.M.C. & $\mathrm{C}$ & 58 & 4 & 2 \\
\hline 4 & Branco & E.M.C. & $\mathrm{C}$ & 44 & 3 & 1 \\
\hline 5 & Branco & E.S.I. & $\mathrm{C}$ & 56 & 3 & 1 \\
\hline 6 & Branco & E.F.C. & $\mathrm{D}$ & 50 & 3 & 1 \\
\hline 7 & Branco & E.M.C. & $\mathrm{C}$ & 62 & 3 & 1 \\
\hline 8 & Branco & E.S.C. & $\mathrm{C}$ & 32 & 2 & 0 \\
\hline 9 & Branco & E.S.C. & $\mathrm{S}$ & 34 & 2 & 0 \\
\hline \multicolumn{4}{|c|}{ Média } & 49,5 & 3 & 1 \\
\hline
\end{tabular}

Fonte: Elaborado pelos autores de acordo com dados da pesquisa.

Legenda: F (feminino); E.F.I. (Ensino Fundamental Incompleto); E.F.C (Ensino Fundamental Completo); E.M.I. (Ensino Médio Incompleto); E.M.C. (Ensino Médio Completo); E.S.I. (Ensino Superior Incompleto); E.S.C. (Ensino Superior Completo); $\mathrm{C}$ (casado); S (solteiro); D (divorciado). 
É interessante destacar a relação entre maternidade e escolaridade. Considerando os dados do IBGE (2014), 44,2\% das mulheres de 15 a 49 anos de idade com 8 anos ou mais de estudo não possuem filhos; enquanto para aquelas com até 7 anos de estudo, a proporção foi de $21,6 \%$. Assim, nota-se que as mulheres com maior escolaridade postergam mais a maternidade ou ainda optam por não terem filhos. Contudo, não se pode desconsiderar a pressão social e cultural sobre as mulheres que não possuem filhos (ALBORNOZ, 1969; HAMPE, 2016).

Em relação à idade, nota-se que há forte presença de mulheres na faixa etária de 50 anos ou mais realizando as atividades domésticas, assim como na faixa etária de 30 a 49 anos, o que é corroborado com o estudo de Bruschini et al. (2011). Entretanto, é importante ressaltar que o nivel de desocupação feminina no Brasil tem sido de declínio nos últimos anos. As taxas de desocupação das mulheres de 25 a 39, de 40 a 49 anos e de 50 anos de idade ou mais reduziram-se no período de 2004 a 2013 , passando de 7,6\%, 5,0\% e 3,2\%, respectivamente, para 6,2\%, $3,7 \%$ e $2,3 \%$, respectivamente (IBGE, 2014), refletindo um cenário onde as muIheres podem estar retornando ao mercado de trabalho após a maternidade, com oferta de creches no país (IBGE, 2010,2012), por exemplo. A seguir é discutido o processo de transição do mercado de trabalho para o exercício da profissão do lar.

\section{A transição do mercado de trabalho para o exercício da profissão do lar}

As profissões exercidas pelas entrevistadas no mercado de trabalho eram de secretária (E3, E5, E7, E8), atendente comercial (E4; E5, E7, E9), empregada doméstica (E6), auxiliar de serviços gerais (E1), cuidador de idosos (E1, E6, E9), babá (E2, E6, E9) e fotógrafa (E2). Em média, o tempo de permanência das entrevistadas no mercado de trabalho foi de 18,3 anos. De forma geral, percebe-se que as profissões exercidas pelas entrevistadas refletiam suas habilidades como donas-de-casa.

A transição do mercado de trabalho para o exercício da profissão do lar deu-se, em todos os casos, por fatores familiares. Dentre os fatores familiares, os principais foram: "priorização da família" (E1, E2, E4, E5), "familiares doentes" (E1, E5, E7, E9), "gravidez" (E2, E4, E7), "filhos pequenos" (E2, E3, E4), "casamento" (E7, E8, E9) e "mudança de cidade" (E2, E5, E6, E9). Os fatores familiares supracitados constituíram elementos fundamentais no processo decisório das entrevistadas abandonarem o mercado de trabalho, o que também é sinalizado por Araújo e Scalon (2005), Bruschini (1985), Bruschini et al. (2011), Madalozzo, Martins e Shiratori (2010) e Melo e Sabbato (2011). Percebe-se que a maioria dos fatores familiares citados ainda representam as responsabilidades históricas atribuídas às mulheres.

Em nenhuma declaração das entrevistadas foram identificadas razões de abandono do mercado de trabalho devido à violência ou violência real e/ou cen- 
suras por parte dos seus maridos, como ocorre no México, de acordo com Funk, Lang e Osterhaus (2005), e na Índia, segundo Kabeer et al. (2012) e Sen (1998). Os principais fatores que levaram as entrevistadas a abandonarem o mercado de trabalho brasileiro foram em razão dos "filhos" e do "casamento", os mesmos que levam as mulheres no México, conforme Calderón e Campos Ríos (2013), e nos Estados Unidos, segundo Hewlett e Luce (2005).

Observa-se que a tarefa de criação e socialização dos filhos ainda permanece tradicionalmente feminina (IBGE, 2012), ocupando lugar de destaque nas responsabilidades das mulheres (SAFFIOTI, 1987; BRUSCHINI, 1998). Pode-se dizer que, para as entrevistadas, a maternidade constituiu um fator familiar determinante para que abandonassem o mercado de trabalho e/ou permanecessem na esfera privada.

Em relação à renda familiar mensal, percebeu-se, com exceção de uma entrevistada aposentada (E7), que a renda principal das entrevistadas provém de apenas um único membro da família: de seus maridos. Isso se dá devido às mulheres exercerem a profissão do lar de forma integral. As entrevistadas (E4, E9) explicaram que devem consultar os seus maridos antes da aquisição de qualquer produto e/ou serviço. Nas palavras das entrevistadas: "Tem que consultar o marido em absolutamente tudo, pois é do bolso dele que sai o dinheiro, não do meu." (E9, ênfase da entrevistada); "Eu peço tudo para o meu marido, pois quem trabalha é ele! Eu ainda falo: 'Amorzinho, está faltando um sofazinho em casa, o que tu acha de comprarmos?"' (E4).

Devido à transição de profissão, os maridos das entrevistadas (E3, E5, E9) assumiram suas dividas com cartões de crédito e carnês de lojas referentes a compras para a família no supermercado e vestuário. Tais dividas eram anteriormente quitadas pelas próprias entrevistadas com a remuneração auferida através do exercicio de atividades profissionais remuneradas no mercado de trabalho.

O poder de compra das entrevistadas foi comprometido em partes (E2, E3, E5, E6, E8) ou totalmente comprometido (E9). No entanto, apesar de terem perdido sua autonomia com relação a decisões de consumo, algumas entrevistadas (E3, E9) percebem aspectos positivos, como o fato de agora terem de controlar a compulsão por compras. Em suas palavras: "Graças a Deus agora eu não posso comprar e isso está servindo para me controlar um pouco." (E3); "Agora eu compro somente o estritamente necessário porque o dinheiro é contadinho." (E9).

Para outras entrevistadas (E1, E2, E4, E5) o poder de compra não foi totalmente comprometido, visto que possuem renda por meio da realização de atividades complementares, e na ausência destas, podem dispor da renda fixa mensal de seus maridos. A entrevistada (E1) utiliza o turno noturno para oferecer aos vizinhos, familiares e amigos diversos produtos, como bijuterias, semijoias, lingeries e vendas por catálogo; a entrevistada (E2) realiza vendas por catálogo; a 
entrevistada (E4) realiza reforma de roupas; e a entrevistada (E5) realiza a venda de doces, bolos e salgados para festas.

Quanto às atividades complementadoras de renda, estas são aceitas pelas entrevistadas e por suas famílias, pois constituem uma forma delas obterem recursos monetários e de adquirirem bens e/ou serviços. Ainda que a informação sobre os ingressos monetários auferidos pelas entrevistadas não tenha sido questionada durante as entrevistas, pode-se dizer que elas beneficiam-se de uma posição de autonomia econômica frente aos seus maridos para pequenos gastos.

Questionou-se às entrevistadas se realizam contribuições mensais à Previdência Social, visando possuir benefícios previdenciários. $O$ desconhecimento aliado à situação econômica familiar confortável da entrevistada (E2) fizeram com que em nenhum momento houvesse contribuído para a Previdência Social, em suas palavras: "Não sabia que eu poderia fazer as contribuições, pois eu achei que somente as pessoas de baixa renda, que estão nos projetos governamentais, poderiam fazer." (E2). De acordo com o MPAS (2015a), a entrevistada (E2) poderia estar realizando contribuições mensais para a Previdência Social por meio do segurado facultativo.

Diferentemente da entrevistada (E2), as entrevistadas (E1, E5, E6, E8) realizam contribuições mensais para a Previdência Social, enquadradas no segurado facultativo. Ainda, as entrevistadas (E3, E4, E9) possuem o interesse em realizar as contribuições mensais o quanto antes, e a entrevistada (E7) realizou poucas contribuições, pois estava esperando completar 60 anos para requerer o benefício de aposentadoria por idade.

Por fim, verificou-se que a maioria das entrevistadas (E1, E2, E4, E5, E6, E7, E9) realizava a jornada dupla de trabalho. Nas palavras de algumas entrevistadas: "Quando eu trabalhei fora, eu chegava em casa e fazia todas as tarefas de casa." (E1); "Eu trabalhava fora e trabalhava em casa também. [...] Eu fazia as duas coisas. Eu fazia a jornada dupla." (E2); "Durante a semana eu chegava tão cansada do trabalho que, às vezes, preparava a janta quase dormindo. Imagina a limpeza diária. A limpeza pesada da casa mesmo era no final de semana." (E7).

Segundo Soares e Sabóia (2007), o ingresso das mulheres no mercado de trabalho brasileiro não necessariamente significa abandonar a realização do trabalho doméstico, sendo a jornada dupla de trabalho uma realidade para muitas delas, conforme Araújo e Scalon (2005). Prova disso são os resultados da última pesquisa realizada pelo IBGE (2014), a qual mostra que as mulheres brasileiras ainda são os individuos que mais realizam a jornada dupla de trabalho ( $88 \%$ para elas; $46 \%$ para eles). A média de horas semanais gastas em afazeres domésticos é apresentada e discutida a seguir.

\section{O (auto)reconhecimento do trabalho no âmbito doméstico pelas profissionais do lar}

Em relação ao tempo de exercício da profissão do lar, as entrevistadas apon- 
tam que realizam os afazeres domésticos há mais de: 34 anos (E1); 25 anos (E2); 20 anos (E3); 16 anos (E4); 21 anos (E5); 28 anos (E6); 32 anos (E7); 4 anos (E8); e 5 anos (E9). O tempo médio de exercício da profissão do lar pelas entrevistadas é de 20,5 anos.

Quanto ao (auto)reconhecimento do trabalho no âmbito doméstico exercido pelas entrevistadas, este resultou em percepções díspares. Por um lado, há o reconhecimento por parte das entrevistadas (E1, E3, E4, E6, E8, E9) e da família das entrevistadas (E1, E3, E4, E6, E8) de que são profissionais do lar. Nas palavras das entrevistadas: "Eu me reconheço como profissional do lar [...] Existe sim um reconhecimento por minha parte e da minha familia do que eu faço." (E1); "Eu sou uma profissional do lar." (E4); "Eu reconheço o que faço. Eu reconheço a minha profissão." (E9); "É uma satisfação pra mim realizar a profissão do lar." (E3, E8).

Por outro lado, as entrevistadas (E2, E5, E7) não se reconhecem como profissionais do lar. As entrevistadas (E2, E5, E7, E9) sentem que as suas familias também não as reconhecem como profissionais do lar, assim como a sociedade em geral. Nas palavras da entrevistada 2: "Eu não consigo reconhecer como um trabalho. [...] Eu não consigo ver como profissão. [...] Os membros da minha familia não me reconhecem como uma profissional do lar." (E2). Percebe-se, mesmo com as manifestações e evoluções sociais promovidas pelas mulheres, que o exercício da profissão do lar ainda precisa ser reconhecido, principalmente pelo próprio individuo que a desempenha, como sinalizado por Melo e Sabbato (2011).

As entrevistadas (E2, E5, E7) destacam que os membros de suas famílias realizam comentários maldosos quando se queixam de estarem cansadas, devido à alta carga de trabalho demandada pelos afazeres domésticos durante o dia. Segundo as entrevistadas, as piadas vão desde: "Tá cansada de quê?" (E2); "Tu não faz nada..." (E7); até "Mas tu só vive em casa!" (E5). Esses comentários são considerados pelas entrevistadas como alguns dos piores insultos que uma mãe, esposa e dona-de-casa pode receber de seu marido e filhos. Neste ponto, percebe-se a invisibilidade e a desvalorização do trabalho doméstico realizado pelas entrevistadas.

Quanto ao supracitado, a literatura acadêmica brasileira sinaliza que parte da desvalorização do trabalho doméstico pela sociedade deve-se ao fato de ser um trabalho não remunerado (MELO; CONSIDERA; SABBATO, 2007; MELO e CASTILHO, 2009; SANTOS, 2008; SANTOS e DINIZ, 2011) e que não contribui monetariamente para o orçamento familiar (BRUSCHINI, 2006; MELO; CONSIDERA; SABBATO, 2007; MELO; CASTILHO, 2009); a outra parte está atrelada a um papel secularmente atribuido às mulheres como uma espécie de "obrigação" (SAFFIOTI, 1969, 1987). Por estas razões é que discussões sobre maneiras de reconhecer o papel dos individuos, especialmente mulheres, na esfera privada são urgentes e importantes. 
Segundo as entrevistadas (E2, E4), a sociedade reconhece como trabalhador o indivíduo que recebe remuneração pelo exercício de atividades (braçal, intelectual), já o indivíduo que não recebe remuneração, não pode ser considerado trabalhador. Nas palavras das entrevistadas: "As pessoas dizem: 'Tu não trabalha?' E eu digo: 'Eu trabalho, eu só não tenho salário." (E2); "As pessoas pensam que a dona-de- casa é a pessoa que não trabalha e que só fica em casa." (E4). Essa visão de trabalho é oriunda da ótica capitalista, à qual descarta o trabalho não remunerado e considera como trabalhador o individuo que emprega a sua força de trabalho no processo de produção de mais-valia (MARX, 1988). As entrevistadas apontam para o fato de que a profissão do lar "não é reconhecida por não ser qualificada como produtora de benefícios econômicos", como sinalizado por Santos (2008, p. 4).

A categoria afazeres domésticos inclui um leque heterogêneo de tarefas que não se enquadram no conceito econômico de trabalho. Dentre as tarefas manuais, as entrevistadas mencionaram: cozinhar, limpar a casa e o pátio, lavar e passar roupa, lavar louça, cozinhar, estender as camas e alimentar os animais de estimação; já as tarefas não-manuais, mencionaram: cuidar dos filhos, fazer as compras no supermercado e feira, administrar o lar e pagar contas mensais. Destaca-se que tais afazeres domésticos perpassam a definição de afazeres domésticos adotada pelo IBGE (2015), mostrando que - conceito utilizado pelo órgão brasileiro é genérico (SOARES; SABÓIA, 2007), o que contribui para que não seja possivel saber exatamente $\circ$ que são os afazeres domésticos (SOARES, 2008; MELO e CASTILHO, 2009).

Para a entrevistada (E1), os afazeres domésticos demandam um número elevado de horas diárias que: "Às vezes, um dia não dá pra fazer tudo e tem vezes que eu faço as coisas pela metade" (E1). Por outro lado, a entrevistada (E3) diz não se importar com o elevado número de horas diárias demandadas pelos afazeres domésticos, visto que os realiza com prazer, e em suas palavras: "Eu gosto de fazer as coisas. Todas. Eu fico até com dores nas costas, mas gosto de ver quando tudo fica limpinho, bonitinho e arrumadinho." (E3). De modo semelhante, posicionaram-se as entrevistadas (E7, E8).

A média de horas diárias gastas em afazeres domésticos pelas entrevistadas é de 4,5; semanalmente, o número de horas chega a 22,5. Este número aproxima-se da média de horas semanais gastas em afazeres domésticos pelas mulheres brasileiras (25,3 horas) e pelas mulheres gaúchas (23,5), de acordo com a pesquisa do IBGE (2014). Neste ponto, é importante refletir sobre as contribuições realizadas por Bruschini (2006), no que diz respeito a considerar os afazeres domésticos como um trabalho não remunerado em vez de inatividade econômica.

As entrevistadas (E1, E2, E4, E5, E6, E7, E8, E9) afirmaram possuir liberdade de realizar os afazeres domésticos quando desejarem, sem qualquer tipo de cobranças, no sentido de desfrutarem o dia com a família, filhos, maridos, amigos e animais de estimação. Nas palavras das entrevistadas: "A casa é minha 
e eu faço a hora que eu quero." (E2); "Depois que eu já fiz [os afazeres domésticos] e se sujarem ou desorganizarem de novo [a casa], eu não limpo e nem organizo. Eu deixo pro outro dia. Vou é aproveitar o dia!" (E5); "Como eu sou a única pessoa que faz as coisas em casa, eu faço quando eu quero e se eu quero." (E9).

Ainda sobre os afazeres domésticos, as entrevistadas (E2, E3, E7, E9) relataram a dificuldade em realizar a divisão destas com seus maridos e/ou com seus filhos, chegando, inclusive, a ser motivo de discussões. Nas palavras das entrevistadas: "Tem dias que eu tô pra cima e pra baixo limpando tudo, e quando eu vejo... o meu marido bem sentado, bem sim senhor. Ah! Já mando pegar uma vassoura e varrer o pátio! Mas... e adianta? É só pra criar briga." (E7); "Eu amo o meu marido, mas eu merecia um marido que me ajudasse a fazer as coisas em casa. Afinal, a casa também é dele!" (E9). No entanto, as próprias entrevistadas relataram que existem atividades cuja realização não pode ocorrer conforme sua vontade, como preparar as refeições da família.

Por outro lado, os maridos e/ou filhos das entrevistadas (E1, E2, E4, E5, E6, E8) contribuem para a realização dos afazeres domésticos, ainda que a participação destes seja menor. Em relação aos filhos, as entrevistadas (E1, E4) construíram o processo de conscientização nestes sobre a importância em "ajudar" na realização dos afazeres domésticos e de preparação individual para o futuro, sem que dependam de terceiros. Nas palavras das entrevistadas: "Quando têm coisas demais para eu fazer, a filha lava a louça, o marido varre a casa, e assim vai. Todo mundo ajuda." (E1); "Os filhos que moram comigo, ajudam em casa. Um lava e o outro cozinha. [...] Isso é para que aprendam, caso um dia vão morar sozinhos, dai já sabem como arrumar a casa e tudo mais." (E4).

Sobre o exposto, Saffioti (1987, p. 15) é enfática ao afirmar que a vida doméstica deve ser partilhada entre homens e mulheres, bem como as atividades que garantem o sustento econômico da família, e não "de ensinar os homens a auxiliarem a mulher no cuidado com os filhos e a casa, pois sempre que a atividade de alguém se configurar como ajuda, a responsabilidade é do outro". Jablonski (2010, p. 270), por sua vez, verificou em seu estudo que as mulheres qualificam a participação de seus maridos nos cuidados com os filhos e na realização de afazeres domésticos como uma "ajuda", sendo "na maioria das vezes, bem-vinda e festejada". Ainda segundo o autor, isso chama a atenção, pois parece que as mulheres não percebem isso como uma questão-problema em relação aos papéis de gênero.

A participação inferior masculina na realização de afazeres domésticos pode ser explicada através da divisão sexual histórica das atividades laborais. Contudo, nos últimos anos mudanças sociais ocorreram e repercutiram sobre a distribuição do tempo dos individuos brasileiros, fazendo com que os homens gastassem mais tempo na realização de afazeres domésticos. Entre 2004 e 2014, por exemplo, a média de horas semanais gastas em afazeres domésticos pelos homens no Brasil aumentou de 10,5 para 10,9 (IBGE, 2006, 2014). Ainda que tímido, o maior en- 
volvimento dos homens na realização de afazeres domésticos não pode ser desprezado, visto que representa uma mudança de comportamento ou de mentalidade em relação à temática (SOARES, 2008; BRUSCHINI e RICOLDI, 2012).

\section{Considerações Finais}

Esta pesquisa buscou identificar as mulheres que migraram do mercado de trabalho para o exercício da profissão do lar em um município gaúcho, no Brasil, bem como os principais fatores para tal atitude, e analisar o (auto)reconhecimento do trabalho no âmbito doméstico pelos indivíduos profissionais do lar. Verificou-se que a transição do mercado de trabalho para o exercício da profissão do lar deu-se, em todos os casos, por fatores familiares, como "priorização da família", "familiares doentes", "gravidez", "filhos pequenos", "casamento" e "mudança de cidade". Isso leva a confirmar que sempre são as mulheres que tomam esta decisão sem outra alternativa. Tais fatores familiares constituíram elementos fundamentais que levaram as mulheres entrevistadas a abandonarem o mercado de trabalho, tendo-se observado que a migração do mercado de trabalho para a profissão do lar ocorreu neste caso somente com mulheres.

Apesar da crescente participação das mulheres no mercado de trabalho brasileiro, percebe-se que o velho padrão ainda vigora: se destina à mulher o espaço privado, tornando-a maior responsável pelos cuidados com a casa, a família e a criação e socialização dos filhos. O envolvimento masculino nos afazeres domésticos e no zelo com os filhos ainda é pequeno, e isso faz com que a média de horas semanais gastas em afazeres domésticos seja maior para as mulheres. A responsabilidade maior do homem continua sendo o sustento econômico do lar. Isto se dá, em partes, devido ao enraizamento dos costumes e das tradições da sociedade.

Quanto ao (auto)reconhecimento do trabalho no âmbito doméstico exercido pelas entrevistadas, percebeu-se que a maioria dessas muIheres se reconhecem como profissionais do lar e afirmam serem reconhecidas também por suas familias, mesmo não sendo reconhecidas pela sociedade. Em contrapartida, houve entrevistadas que não se reconhecem como profissionais do lar e sentem que suas famílias, assim como a sociedade em geral, também não as reconhecem. Devido ao trabalho doméstico ser historicamente atribuição feminina, sua desvalorização deriva do papel inferior a que foi relegada a mulher no passado. Por esta razão, fazem-se necessárias discussões sobre as formas de reconhecer o papel da mulher na esfera privada.

\section{Referências}

ALBORNOZ, S. Educação: Reflexões e Prática. São Paulo: Herder, 1969. 
ARAÚJO, C. et al. Estudo de Caso. Métodos de Investigação em Educação. Instituto de Educação e Psicologia, Universidade do Minho, 2008.

ARAÚJO, C.; SCALON, C. (Orgs.). Gênero, família e trabalho no Brasil. Rio de Janeiro: Editora FGV, 2005.

BARDIN, L. Análise de conteúdo. São Paulo: Edições 70, 2011.

BRASIL. Diário Oficial da União. Lei n. 8.212, de 24 de julho de 1991. Dispõe sobre a organização da Seguridade Social, institui Plano de Custeio, e dá outras providências. Brasilia, DF, 1991.

Ministério da Previdência e Assistência Social. Inscrição da Previdência Social. Brasilia, DF, 2015a. Disponivel em: <http://www.mpas.gov.br/>. Acesso em: jun. de 2014.

Ministério da Previdência e Assistência Social. Aposentadoria por idade. Brasilia, DF, 2015b. Disponivel em: <http://www.previdencia.gov.br/arquivos/office/3_100701-165315-945.pdf>. Acesso em: jul. de 2014.

Ministério do Trabalho e Emprego. Classificação Brasileira de Ocupações. Brasilia, DF, 2014. Disponivel em: <http://www.mtecbo.gov.br/cbosite/pages/home.jsf>. Acesso em: jun. de 2014.

BRUSCHINI, C. Mulher e trabalho: uma avaliação da década da mulher. São Paulo: Nobel, 1985.

Desigualdades de gênero no mercado de trabalho brasileiro: o trabalho da muIher no Brasil e nas regiões nordeste e sudeste na década de oitenta. In: LIGOCKI, M.S. L.; LIBARDONI, M. (Coords.). Discriminação positiva, ações afirmativas: em busca da igualdade. 2. ed. p. 87-118, São Paulo: CFEMEA/Elas, 1996.

Trabalho das mulheres e mudanças no período 1985-1995. 78p., Textos FCC, n. 17. São Paulo: FCC/DPE, 1998.

Trabalho doméstico: inatividade econômica ou trabalho não remunerado? Revista Brasileira de Estudos de População, Pampulha, v. 24, n. esp., 2006.

Trabalho e gênero no Brasil nos últimos dez anos. Cadernos de Pesquisa, São Paulo, v. 37, n. 132, p. 537-572, 2007.

BRUSCHINI, C. et al. Trabalho, renda e políticas sociais: avanços e desafios. In: BARSTED, L. L.; PITANGUY, J. (Orgs.). O Progresso das Mulheres no Brasil 2003-2010. Cap. 7, p. 142-177. Rio de Janeiro: CEPia; Brasilia: ONU Mulheres, 2011. 
BRUSCHINI, C.; RICOLDI, A. M. Revendo estereótipos: o papel dos homens no trabalho doméstico. Estudos Feministas, Florianópolis, v. 20, n. 1, p. 259-87, jan.,/ abr., 2012.

CALDERÓN, Y. P.; CAMPOS RÍOS, G. Las Mujeres Jóvenes en México: ¿Estudian o Trabajan? Última década, Santiago, v. 21, n. 39, p. 63-83, dec., 2013.

CAMARANO, A. A. PNAD 2009 - Primeiras Análises: tendências demográficas. Comunicados do IPEA n. 64, 2010.

CARVALHO, M. P. de. O conceito de gênero: uma leitura com base nos trabalhos do GT Sociologia da Educação da ANPED (1999-2009). Revista Brasileira de Educação, Rio de Janeiro, v. 16, n. 46, jan./abr., 2011.

COLLIS, J.; HUSSEY, R. Pesquisa em administração: um guia prático para alunos de graduação e pós-graduação. 2. ed. Porto Alegre, Bookman, 2005.

CRESWELL, J. W. Projeto de pesquisa: métodos qualitativo, quantitativo e misto. 2 ed. Porto Alegre: Artmed, 2007.

DINIZ, G. Mulher, trabalho e saúde mental. In: CODO, W. (Org.). O Trabalho enlouquece? Um encontro entre a clínica e o trabalho. p. 138-195. Petrópolis: Vozes, 2004.

DURAN, M. A. A dona-de-casa: crítica política da economia doméstica. Coleção Tendências, v. 5, Rio de Janeiro: Edições Graal, 1983.

FUNK, A.; LANG, J. L.; OSTERHAUS, J. Ending Violence against Women and Girls - Protecting Human Rights: Good Practices for Development Cooperation. Deutsche Gesellschaft für Internationale Zusammenarbeit, Planning and Development Department Governance and Democracy, Eschborn, Alemanha, 2005.

GIL, A. C. Métodos e técnicas de pesquisa social. 6a ed. $5 a$ reimpr. São Paulo: Atlas, 2012.

HAIR, J. F. et al. Fundamentos de métodos de pesquisa em administração. Porto Alegre: Bookman, 2005.

HAMPE, F. Sejamos tod@s feministas: interseccionalidade, direitos humanos e educação. In: SILVA, F. F. da; BONETTI, A. de L. (Orgs.). Gênero, interseccionalidades e feminismos: desafios contemporâneos para a Educação. São Leopoldo: Oikos, 2016.

HEWLETT, S. A.; LUCE, C. B. Off-Ramps And On-Ramps: Keeping Talented Women On The Road To Success. Harvard Business Review, Massachusetts, v. 83, n. 3 , p. 43-54, mar., 2005. 
INSTITUTO BRASILEIRO DE GEOGRAFIA E ESTATÍSTICA (IBGE). Sintese de indicadores sociais: 2005. 330p. Rio de Janeiro: IBGE, 2006.

Pesquisa nacional por amostra de domicilios: síntese de indicadores 2009. 289p. Rio de Janeiro: IBGE, 2010a.

Sintese de indicadores sociais: uma análise das condições de vida da população brasileira: 2010. Rio de Janeiro: IBGE, 2010b.

Sintese de indicadores sociais: uma análise das condições de vida da população brasileira: 2012. 293p. Rio de Janeiro: IBGE, 2012.

Sintese de indicadores sociais: uma análise das condições de vida da população brasileira: 2014. 214p. Rio de Janeiro: IBGE, 2014.

Sintese de indicadores sociais: uma análise das condições de vida da população brasileira: 2015. 134p. Rio de Janeiro: IBGE, 2015.

JABLONSKI, B. A Divisão de Tarefas Domésticas entre Homens e Mulheres no Cotidiano do Casamento. Psicologia Ciência e Profissão, Brasília, v. 30, n. 2, p. 262275, 2010.

KABEER, N. et al. Productive Safety Nets for Women in Extreme Poverty: Lessons from Pilot Projects in India and Pakistan. Discussion Paper 28/12. University of London, School of Oriental and African Studies, Centre for Development Policy and Research, Londres, 2012.

MADALOZZO, R.; MARTINS, S.; SHIRATORI, L. Participação no mercado de trabalho e no mercado doméstico: homens e mulheres têm condições iguais? Estudos Feministas, Florianópolis, v. 18, n. 2, p. 547-566, 2010.

MARX, K. O capital: crítica da economia política. V. I. São Paulo. Nova Cultural. 1988.

MELO, H. P. de; CONSIDERA, C. M.; SABBATO, A. D. Os afazeres domésticos contam. Economia e Sociedade, Campinas, v. 16, n. 3, p. 435-454, dez., 2007.

; CASTILHO, M. Trabalho reprodutivo no Brasil: Quem faz? Revista Economia Contemporânea, Rio de Janeiro, v. 13, n. 1, p. 135-158, jan./abr., 2009

; SABBATO, A. D. Trabalhadoras domésticas: eterna ocupação feminina. Até quando? In: BARSTED, L. L.; PITANGUY, J. (Orgs.). O Progresso das Mulheres no Brasil 2003-2010. Cap. 8, p. 179-185. Rio de Janeiro: CEPia; Brasillia: ONU Mulheres, 2011.

MORAES, R. Análise de conteúdo. Revista Educação, Porto Alegre, v. 22, n. 37, p. 
7-32, 1999.

SAFFIOTI, H. I. B. A mulher na sociedade de classes: mito e realidade. São Paulo: Quatro Artes, 1969.

O poder do macho. São Paulo: Moderna, 1987.

SANTOS, L. da S. Profissão: Do Lar. A (des)valorização do trabalho doméstico como desdobramento da (in)visibilidade do feminino. Dissertação. (Mestrado em Psicologia Clínica e Cultura). Programa de Pós-Graduação em Psicologia Clínica e Cultura, Brasilia, DF, Brasil, 2008.

SANTOS, L. da S.; DINIZ, G. R. S. Donas de casa: classes diferentes, experiências desiguais. Psicologia Clínica, Rio de Janeiro, n. 23, v. 2, p. 137-149, 2011.

SCHLICKMANN, E.; PIZARRO, D. A evolução da mulher no trabalho: uma abordagem sob a ótica da liderança. Revista Borges, Florianópolis, v. 3, n. 1, jul., 2013.

SEN, P. Development practice and violence against women. Gender and Development, Oxford, v. 6, n. 3, p. 7-16, 1998.

SOARES, C.; SABÓIA, A. L. Tempo, trabalho e afazeres domésticos: um estudo com base nos dados da Pesquisa Nacional por Amostra de Domicílios de 2001 e 2005. (Textos para discussão. Diretoria de pesquisas, n. 21), Rio de Janeiro: IBGE, Coordenação de População e Indicadores Sociais, 2007.

A distribuição do tempo dedicado aos afazeres domésticos entre homens e mulheres no âmbito da familia. Revista Gênero, Niterói, v. 9, n. 1, p. 9-29, jul./dez., 2008.

PROGRAMA DE LAS NACIONES UNIDAS PARA EL DESARROLLO (PNUD). Trabajo Al Servicio Del Desarrollo Humano. El PNUD insta a "hacer frente a los desafíos y aprovechar las oportunidades del nuevo mundo del trabajo". Disponivel em: <http://www.undp.org/content/undp/es/home/presscenter/pressreleases/2015/12/14/-address-challenges-and-seize-opportunities-of-the-new-world-of-work-undp-urges.html>. Acesso em: dez. de 2015.

YIN, R. K. Estudo de caso: planejamento e métodos. 4. ed. Porto Alegre: Bookman, 2010.

Recebido em fevereiro de 2017

Aprovado em agosto de 2018 